ISSN 2447-9071

doi $10.36414 /$ rbmc.v6i14.36
Contato para correspondência:

Patricia dos Santos

E-mail:

profpatricia.letras@gmail.com

Conflito de interesse: Não

Financiamento: Coordenação de Aperfeiçoamento de Pessoal de Nível Superior - CAPES

Recebido: 03/04/2020

Aprovado: 06/04/2020

\section{O trabalho com produção textual no ensino médio sob o olhar da linguística do texto e da pesquisa-ação}

\section{The work with textual production in middle education under the view of textual language and research}

\author{
Patricia dos Santos ${ }^{1,2}$, Vaima Regina Alves Motta \\ 1 Universidade Federal de Santa Maria - UFSM \\ ${ }^{2}$ Faculdade da Polícia Militar - FPM
}

\section{Resumo}

O presente estudo diz respeito ao trabalho com produção textual na Educação Básica, mais precisamente com estudantes de Ensino Médio. As principais teorias que fundamentam o trabalho são a Linguística do Texto e a Pesquisa-ação. Objetivamos, neste estudo, apresentar os resultados de encaminhamento de processo de escrita desenvolvido em sala de aula, advindo da articulação entre a Linguística do Texto ea Pesquisa-ação para o trabalho com produção textual com estudantes de Ensino Médio. Nesse sentido, as reflexões aqui evidenciadas referem-se ao encaminhamento do processo de escrita pautado por referencial teórico-metodológico que privilegia a interação e a reflexãono processo de ensino e aprendizagem de textos na escola. No que tange aos resultados, entendemos que houve aprimoramento da escrita argumentativa dos estudantes investigados.

Palavras-Chave: Produção textual, Ensino médio, Linguística do texto.

\begin{abstract}
The present study concerns the work with textual production in Basic Education, more precisely with high schoolstudents. The main theories that support the work are Text Linguistics and Action Research. In this study, we aim to present the results of the forwarding of the writing process developed in the classroom, arising from the articulation between Text Linguistics and Action Research for working with textual production with high school students. In this sense, the reflections shown here refer to the forwarding of the writing process guided by theoretical-methodological framework that favors interaction and reflection in the process of teaching and learning texts at school. Regarding the results, we understand that there was an improvement in the argumentative writing of the investigated students.
\end{abstract}

Keywords: Text production, High school, Linguistics of the text. 


\section{Introdução}

Inauguramos esta seção registrando que, em nossa pesquisa de mestrado $A$ intertextualidade na produção escrita de estudantes do Ensino Médio - a Linguística do Texto e a Pesquisaação na escola, adotamos, dentre outros referenciais teóricos e metodológicos para o trabalho com o texto em sala de aula, a Linguística do Texto e a Pesquisa-ação. Nossa pesquisa oportunizou oficinas de produção textual a estudantes de Ensino Médio de escola da rede pública de Santa Maria-RS. Para a dinamização das oficinas, elegemos a Linguística do Texto, o Process Writing e a Pesquisa-ação como embasamento norteador de nossas práticas, haja vista que tais teorias concebem o texto enquanto processo de ensino e porque privilegiam o trabalho, em sala de aula, de modo participativo e corresponsável.

Assim, para o presente artigo, decidimos apresentar os resultados do passo a passo do processo de produção textual ocorrido em sala de aula, a partir dos postulados da Linguística do Texto e da Pesquisa-ação, Com isso, nosso intuito é o de, também, fomentar a discussão sobre o processo de ensino e aprendizagem de textos na Educação Básica, especialmente com estudantes de Ensino Médio. Nesse sentido, fica o convite à leitura e ao diálogo acerca das reflexões aqui evidenciadas.

De acordo com nosso entendimento, a produção de texto em sala de aula é uma atividade da mais alta importância para o conhecimento e a prática educacional de estudantes em todos os níveis de ensino. A produção textual possibilita-lhes, assim, a manifestação de suas ideias, por meio da linguagem escrita, deixando estes de serem apenas leitores, para serem, também, produtores de textos.

Logo, o que nos impulsiona investigar/estudar a produção textual na escola, considerando nossas experiências profissionais com o ensino de Língua Portuguesa e de Produção de Textos - com estudantes de Ensino Médio -, é o fato de que o texto há muito tem tido conotação e enfoque de simples produto $^{1-3}$. O texto é, principalmente, "processo"4.

Dessa forma, nós, enquanto professoras e pesquisadoras, percebemos que o trabalho de pesquisa na Escola de Educação Básica se faz extremamente relevante, haja vista a própria demanda escolar e porque entendemos que, com relação à produção de textos (orais ou escritos), a escola precisa de ações/investimentos que visem à qualificação do texto no ambiente educacional. Seguindo essa linha de raciocínio, entendemos, sobretudo, que escrever é uma atividade de interação e reflexão, logo precisa ser priorizada e administrada, pelo professor, de modo contínuo e intencional no que se refere ao encaminhamento metodológico.

Por compreendermos a importância do trabalho com produção textual, em sala de aula, na perspectiva de texto como um processo, e no trabalho com gêneros textuais, partimos da premissa de que "aprender a produzir textos não é um trabalho solitário ou fruto de uma fagulha casual que de repente acontece como se fosse mágica" (p. 159) ${ }^{5}$. Afirma, ainda, "que a sala de aula nada mais é do que o encontro entre o particular e o coletivo" (p. 41)

Nessa senda, reiteramos que, por acreditarmos no trabalho e na parceria entre universidade e escola pública, aproximamos nossa pesquisa de pós-graduação do contexto escolar quando propomos pesquisa-ação. Partimos dessa concepção, pois acreditamos que um aporte teórico e metodológico voltado para o trabalho com o texto, em sala de aula, possibilita um processo de ensino e aprendizagem mais coparticipativo e mais corresponsável no que se refere aos papeis de professor e estudantes no processo de produção escrita.

Nesse viés, apresentamos, a seguir, o referencial teóricometodológico e os principais autores que norteiam as reflexões do presente artigo. Assim, exploramos, na sequência, os postulados da Linguística do Texto com seu percurso histórico, bem como sua definição de texto, sujeito e contexto.

\section{Linguística do Texto - Percurso Histórico}

Sobre a Linguística do Texto (LT), "a linguística textual constitui um novo ramo da linguística, que começou a desenvolver-se na década de 1960, na Europa e, de modo especial, na Alemanha" (p. 15) ${ }^{6}$. O termo Linguística Textual pode ser encontrado em Cosériu em 1955, porém, no sentido que é atualmente atribuído, foi o autor Harald Weinrich em 19661967 quem o empregou pela primeira vez ${ }^{6}$.

Nesse viés, destacamos que, "anteriormente à década de 1960 , as pesquisas linguísticas tinham como limite o estudo da frase - fonologia, morfologia e sintaxe frasal -, desconhecendo os aspectos semânticos e contextuais em diferentes situações de comunicação" (p. 11) 7 .

A LT, tal como pode ser concebida hoje, já passou por três grandes momentos durante sua evolução. Em seu histórico, a LT concebeu diferentes conceitos de texto8. Entre os anos 1960 e 1970, numa abordagem sintático-semântica, o texto era percebido como frase complexa. Seu foco de estudo era a coerência e a coesão; ou seja, nesse primeiro momento, o interesse predominante era o da análise transfrástica, limitada ao nível da frase, isto é, partia-se da frase para o texto, exatamente por preocuparem-se com as relações que se estabelecem entre frases e períodos, de forma a construir unidade de sentido?.

Na segunda metade dos anos 1970, com o surgimento de teorias comunicativas, adotou-se a concepção de texto como ato de fala complexo, tido como parte do processo e não mais como um produto acabado (perspectiva pragmática) ${ }^{8}$. Nesse 
segundo momento, entendeu-se a descrição da competência textual, tida como a competência específica do falante ${ }^{9}$."Postulava-se o texto como unidade teórica formalmente construída, em oposição ao discurso, unidade funcional, comunicativa e intersubjetivamente construída" (p. 249)9.

Já nos anos 1980, ampliou-se a ideia de coerência - fenômeno construído em situação de interação em decorrência de aspectos linguísticos, cognitivos e socioculturais ${ }^{8}$. Nesse terceiro momento, o texto passa a ser entendido em seu contexto de produção e a ser compreendido como um processo, resultado de operações comunicativas e processos linguísticos em situações sociocomunicativas.

Essa nova etapa no desenvolvimento da Linguística de Texto decorre de uma nova concepção de língua - não mais um sistema virtual autônomo, um conjunto de possibilidades, mas um sistema real, usado em determinados contextos comunicativos -; e um novo conceito de texto - não mais encarado como um produto pronto e acabado, mas um processo, uma unidade em construção. A LT, nesse estágio de sua evolução, assume nitidamente uma feição interdisciplinar, dinâmica, funcional e processual ${ }^{10}$.

Ainda em consonância, "a partir da década de 1980, a 'virada cognitiva' da LT fez ver o texto como o resultado da ativação de processos mentais" (p. 318) ${ }^{8}$. Contudo, em 1990, aconteceu a chamada "virada discursiva" e, numa perspectiva bakhtiniana, a LT incorporou uma concepção sociocognitiva interacional/dialógica da língua.

\footnotetext{
Portanto, na concepção interacional (dialógica) da língua, na qual os sujeitos são vistos como atores/construtores sociais, o texto passa a ser considerado o próprio lugar da interação e os interlocutores, sujeitos ativos que - dialogicamente - nele se constroem e por ele são construídos (p. 44) ${ }^{11}$.
}

Por compreender a língua numa perspectiva dialógica, isto é, de interação, entende-se que o texto vem a ser esse lugar de interação entre os sujeitos que, por sua vez, são considerados ativos, no texto se constroem e pelo texto são construídos. Nesse ínterim, tanto autor quanto leitor do texto são percebidos como protagonistas, os quais interagem por meio da materialidade linguística.

No final da década de 1970, a palavra de ordem não era mais a gramática de texto, e sim a noção de textualidade ${ }^{10}$. Foram propostos sete critérios de textualidade, a saber: coesão, coerência, intencionalidade, aceitabilidade, informatividade, situacionalidade e intertextualidade ${ }^{12}$.

Afirma-se que a Linguística do Texto "dispõe de um dogma de fé: o texto - unidade linguisticamente superior à frase - $\mathrm{e}$ uma certeza: a gramática de frase não dá conta do texto" (p. $16)^{13}$. No que tange à Linguística do Texto:

\footnotetext{
[...] como toda e qualquer ciência, tem evidentemente os seus limites. Sua preocupação maior é o texto, envolvendo, pois, todas as ações linguísticas, cognitivas e sociais envolvidas em sua organização, produção, compreensão e funcionamento no seio social. Tais questões, contudo, só a interessam na medida em que ajudam a explicar o seu objeto de estudo - o TEXTO - e não a sociedade, a mente, a História, objetos que são de outras ciências afins (p. 2)14.
}

O que se propõe é que se entenda que o interesse maior da Linguística do Texto é o texto e tudo o que lhe diz respeito: seu modo de produção, de recepção e de interpretação, envolvendo, também, escritor e leitor, ou seja, quem produz e quem recebe o texto ${ }^{14}$.

Apresentamos, na sequência, as definições de importantes conceitos para a Linguística do Texto: conceito de texto, conceito de sujeito e conceito de contexto. Tais definições e esclarecimentos revelam nosso ponto de vista acerca de importantes questões que envolvem a sala de aula: o texto, 0 estudante e seu contexto de produção.

\section{Definição de texto, sujeito e contexto}

Acerca dos postulados sobre o texto, afirma-se "que o falante [...] se comunica através de textos e não de frases" ( $p$. $12)^{7}$, haja vista que a LT trata dos processos e regularidades gerais e específicos, segundo os quais se produz, constitui, compreende e descreve o fenômeno texto. $O$ texto é uma ocorrência comunicativa e a LT, por sua vez, "trata o texto como um ato de comunicação unificado num complexo universo de ações humanas" (p. 33) ${ }^{7}$.

Evidencia ainda que, justamente por se apresentar a Linguística do Texto como o estudo das operações linguísticas e cognitivas relativas ao texto, o próprio texto ativa estratégias, expectativas e conhecimentos linguísticos e não linguísticos. A LT assume, assim, importância decisiva no ensino de língua? De maneira mais enfática, o estudioso propõe que se veja a LT como "o estudo das operações linguísticas e cognitivas reguladoras e controladoras da produção, construção, funcionamento e recepção de textos escritos ou orais" (p. 33) ${ }^{7}$.

Dessa forma, existe uma concepção segundo a qual a escrita é vista como produção textual, cuja realização exige do produtor a ativação de conhecimentos e a mobilização de várias estratégias. Isso significa que o produtor "pensa" no que vai escrever e em seu leitor, depois escreve, lê, revê ou reescreve em um movimento constante guiado pelo princípio interacional ${ }^{3}$. 
Nesse viés, defende-se que o texto seja entendido como objeto central do ensino. Para a estudiosa, interessa que sejam priorizados, nas aulas de língua portuguesa, exercícios de leitura e produção de textos, os quais auxiliam o estudante a pensar sobre os usos da língua nas diversas situações de interação ${ }^{14}$.

A definição de texto deve levar em conta alguns princípios fundamentais. Esses princípios concentram-se em: a) a produção textual é uma atividade verbal, pois os falantes, ao produzirem um texto, estão efetuando ações; b) a produção textual é uma atividade verbal consciente, ou seja, é uma atividade intencional, pois o falante dará a entender seus propósitos, sempre considerando as condições em que tal atividade é realizada; e c) a produção textual é uma atividade interacional, haja vista que os interlocutores estão envolvidos, de diferentes maneiras, nos processos de construção e interpretação de textos9. Sobre o conceito de sujeito, apresentamos as palavras:

\footnotetext{
[...] à concepção de língua como lugar de interação corresponde a noção de sujeito como entidade psicossocial, sublinhando-se o caráter ativo dos sujeitos na produção mesma do social e da interação e defendendo a posição de que os sujeitos (re)produzem o social na medida em que participam ativamente da definição da situação na qual se acham engajados [...] (p. 15)' .
}

Compreendemos, assim, que é no texto - considerado lugar de interação - e não na frase que o sujeito tem a oportunidade de potencializar ações de interação, especialmente se pensarmos na sala de aula (lugar social ao qual o presente trabalho está se reportando). Segundo a concepção interacional/dialógica da língua, os sujeitos são vistos como atores/ construtores sociais, sujeitos ativos que - dialogicamente - no texto se constroem e por ele são construídos. Tanto quem produz como quem interpreta o texto são estrategistas, pois mobilizam várias estratégias de ordem sociocognitiva, interacional e textual, visando à produção de sentido'.

Para o"jogo da linguagem" tem-se o produtor/planejador, que objetiva viabilizar seu "projeto de dizer", orientando o interlocutor por meio de indícios e/ou marcas para a construção de sentidos. Nesse sentido, o texto sinaliza limites quanto às leituras que possam ser feitas; e o leitor/ouvinte irá processar a construção dos sentidos no texto'.

Depois dos estudos sobre o texto e o sujeito, salienta-se que é também importante para a LT o contexto, isto é, o conjunto de condições externas à língua. Esses elementos são necessários para a produção, recepção e interpretação de texto, bem como a interação, uma vez que o sentido não está no texto, mas acontece na troca entre o escritor/falante e o leitor/ouvinte ${ }^{10}$.
O contexto abrange não apenas os conhecimentos linguísticos/gramaticais - o co-texto -, como, também, as situações de interação imediata e mediata. Entretanto, aos poucos, um outro contexto foi evidenciado no interior da LT: o contexto sociocognitivo, que engloba todos os tipos de conhecimentos guardados na memória dos sujeitos e que necessitam ser mobilizados3. "Esses conhecimentos, resultado de inúmeras atividades em que nos envolvemos ao longo de nossa vida, deixam entrever a intrínseca relação entre linguagem/mundo/ práticas sociais" (p. 37)

O conhecimento linguístico abrange os conhecimentos gramatical e lexical; diz respeito à organização do material linguístico expresso no texto. O conhecimento enciclopédico/conhecimento de mundo, se encontra armazenado na memória dos sujeitos. O conhecimento sobre modelos textuais globais permite aos falantes o reconhecimento de textos como se fossem exemplares de determinado gênero ou tipo textual. Já o conhecimento sociointeracional trata das formas de interação por meio da linguagem ${ }^{11}$.

Nesse sentido, abordamos, a seguir, os embasamentos da Pesquisa-ação, metodologia de pesquisa adotada para o referido trabalho e que oportuniza trabalho corresponsável e colaborativo em sala de aula.

\section{Métodos}

A metodologia adotada neste trabalho prioriza a interação e a reflexão entre os sujeitos envolvidos no processo de ensino e aprendizagem de textos, em sala de aula, a qual acredita que a pesquisa-ação se configura numa importante abordagem para o desenvolvimento e aperfeiçoamento de professores, além de proporcionar ferramentas para a melhoria do ensino em ambientes educativos e crescimento do professor/pesquisador ${ }^{15}$. A pesquisa-ação é um processo estruturado de investigação de situações/preocupações práticas de um contexto específico de ensino e, para tanto, é apropriada a colaboração dos envolvidos, que juntos poderão evidenciar possibilidades de mudança ${ }^{15}$.

Entendemos ainda que a pesquisa-ação é uma metodologia que responde às nossas expectativas enquanto pesquisa $\mathrm{e}$ enquanto prática de ensino a ser desenvolvida, e por acreditarmos, também, que a pesquisa-ação se configura como uma construção que une a compreensão dos pesquisadores e dos sujeitos envolvidos na pesquisa ${ }^{16}$. A pesquisa-ação, além da participação, supõe uma forma de ação planejada de caráter social, educacional ${ }^{16}$. Defende-se a ideia de que a pesquisa-ação consiste em esclarecer problemas sociais e técnicos, pertinentes cientificamente, por meio de grupos e parceiros interessados na resolução dos problemas levantados e/ou no avanço para que as respostas formuladas sejam as mais adequadas ${ }^{16}$. 
Do ponto de vista sociológico, a proposta de pesquisa-ação dá ênfase à análise das diferentes formas de ação. Os aspectos estruturais da realidade social não podem ficar desconhecidos, a ação só se manifesta num conjunto de relações sociais estruturalmente determinadas (p. 15) ${ }^{16}$.

Em relação aos fatos sociais, argumenta-se que a pesquisaação é um tipo de estudo adequado às formas de agir no mundo, haja vista que uma de suas premissas, a ação - na pesquisa -, precisa ser revelada no âmbito dos aspectos que estruturam a realidade social subjacente.

Sobre as definições possíveis de pesquisa-ação, esclarece-se que esse tipo de pesquisa se enquadra como pesquisa social, que é realizada em parceria com uma ação ou uma resolução de um problema coletivo no qual tanto pesquisadores como participantes estão envolvidos de modo cooperativo/participativo ${ }^{16}$. Na pesquisa-ação, os pesquisadores têm um papel ativo no equacionamento dos problemas observados, no acompanhamento e na avaliação das ações apresentadas em função dos problemas ${ }^{16}$.

Para melhor compreensão, apresenta-se alguns dos principais aspectos a serem considerados nesse tipo de pesquisa, uma vez que a pesquisa-ação é uma estratégia metodológica da pesquisa social: a) ampla e explícita interação entre pesquisadores e sujeitos envolvidos na situação; b) senso de prioridade em relação aos problemas a serem investigados e das soluções a serem apresentadas sob forma de ação concreta; c) o objeto de investigação é constituído pela situação social e pelos problemas de naturezas diversas encontrados; d) é objetivo da pesquisa-ação resolver/esclarecer os problemas da situação observada; e) acompanhamento de decisões, ações e de toda atividade de cunho intencional dos agentes da situação; ef) almeja-se ampliar o conhecimento dos pesquisadores e o nível de consciência das pessoas/grupos considerados ${ }^{16}$.

Quanto ao ponto de vista científico, evidencia-se que a pesquisa-ação vem a ser uma proposta metodológica e técnica que fornece meios para orientar a pesquisa social aplicada, pois com ela há a possibilidade de uma maior flexibilidade na concepção e aplicação dos meios concretos de investigação ${ }^{16}$.

A compreensão da situação, a seleção dos problemas, a busca de soluções internas, a aprendizagem dos participantes, todas as características qualitativas da pesquisa-ação não fogem ao espírito científico. O qualitativo e o diálogo não são anticientíficos (p. 30)16.

Certamente, a pesquisa-ação é uma metodologia que privilegia, durante o desenvolvimento de sua prática, a interação, a colaboração e a reflexão dos sujeitos envolvidos na situação investigada, pois possibilita que tanto pesquisador como participantes de pesquisa atuem de modo corresponsável.
Reforça-se que a pesquisa-ação pode ser percebida como uma maneira de conceber e organizar uma investigação de finalidade prática e que se apresente conforme as exigências da ação/participação dos envolvidos na situação investigada, "é necessário produzir conhecimentos, adquirir experiência, contribuir para a discussão ou fazer avançar o debate acerca das questões abordadas" (p. 28) ${ }^{16}$. Afirma-se, ainda, que, em se tratando de pesquisa social aplicada, e em especial sobre pesquisa-ação, os problemas levantados são também de ordem prática; interessa, nesse sentido, procurar soluções para se atingir um objetivo ou realizar uma possível transformação dentro do quadro observado ${ }^{16}$. Eis a formulação proposta: a) análise e delimitação do quadro inicial; b) delineamento da situação final; c) identificação dos problemas a serem resolvidos para que as ideias anteriores possam acontecer ('a'e'b'); c) planejamento de ações; e e) realização e avaliação das ações ${ }^{16}$.

Destaca-se que a pesquisa-ação necessita ser articulada dentro de uma problemática com um aporte de referência teórica, pois o papel da teoria consiste em criar ideias/hipóteses a fim de orientar a pesquisa e as interpretações ${ }^{16}$. Pontua-se que "certos elementos teóricos deverão ser adaptados e'traduzidos' em linguagem comum para permitir um certo nível de compreensão" (p. 64) ${ }^{16}$. Seguindo esse raciocínio, argumenta-se que "[...] trata-se de conhecer para agir, de agir para transformar" (p. 106) ${ }^{16}$. Ou seja, a ação remete a uma tomada de consciência da situação e, assim, espera-se que tal ação corrobore outras, transformando, (re)significando as atividades sociais ${ }^{16}$.

\section{Resultados e Discussão}

Para a referida pesquisa, registramos nos planos de aula o modelo de unidade do processo de escrita elaborado por nós para dinamizarmos nas oficinas com os estudantes do $2^{\circ}$ ano do Ensino Médio, de uma escola da rede estadual de Santa Maria-RS, durante os meses de junho a outubro de 2015. Foram ministradas doze oficinas de produção textual, nas dependências do colégio, às quintas-feiras, das $13 \mathrm{~h} 30 \mathrm{~min}$ às $15 \mathrm{~h} 30 \mathrm{~min}$, no contra turno das aulas dos estudantes.

No que tange às produções textuais, os estudantes realizaram, ao todo, uma sequência de três escritas sobre o mesmo assunto: a primeira escrita, a reescrita e a escrita final dos textos com base na metodologia do Process Writing ${ }^{4}$. Os gêneros textuais trabalhados nas oficinas foram os do campo argumentativo - redação do ENEM, artigo de opinião e carta aberta ${ }^{17}$.

As oficinas basearam-se nos seguintes passos: $1^{\circ}$ ) leitura de textos motivadores; $2^{\circ}$ ) debate e argumentação; $3^{\circ}$ ) primeira escrita e avaliação/feedback; $4^{\circ}$ ) reescrita e avaliação/feedback; e 5o) escrita final e avaliação/feedback. Sobre a leitura de textos motivadores, as temáticas trabalhadas foram As redes sociais 
ajudam ou atrapalham as relações pessoais? para a redação do ENEM, Intolerância Religiosa para o artigo de opinião e Escassez de recursos naturais (água e florestas) para a carta aberta.

Logo após a leitura dos textos base, que acontecia ora individualmente, ora de modo compartilhado entre os estudantes, a professora mediava o debate por meio de reflexão e de perguntas acerca dos referidos assuntos/textos. Nesse sentido, os estudantes eram convidados - em duplas ou individualmente - a expressarem seus posicionamentos e a ampliarem a discussão sobre os assuntos em questão, uma vez que todos tinham a oportunidade de se manifestarem e de realizarem trocas de opinião entre si, sempre respeitando os diferentes pontos de vista existentes.

Tão logo os momentos de leitura dos textos e posterior debate e, os estudantes eram convidados pela professorapesquisadora a produzirem seus próprios textos acerca dos assuntos tratados. Destacamos, nesse sentido, que os estudantes realizavam rascunhos e só depois de conferirem/revisarem seus textos, registravam, então, em folha a ser entregue à professora.

Haja vista nosso propósito para o presente artigo, bem como adequação no que se refere ao espaço/número de páginas, apresentamos, a seguir, para fins de exemplificação e socialização, a primeira e a última escrita do artigo de opinião escrito pelo sujeito de nossa pesquisa, intitulado "Estudante Z".

1a Escrita - Artigo de Opinião (Intolerância Religiosa) "Estudante Z" 1a Escrita - Artigo de Opinião (Intolerância Religiosa) - "Estudante Z"

\section{$20 / 08 / 15$}

A intolerância relegiosa mäo i um probulema recente. bla sempre stare presente na sociedade, um des maioles

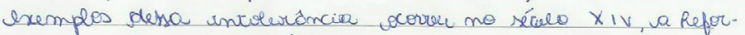
ma, que foi um grondre marimento deo prolestombes. Conbra a igreja vatólica, uqu na época era detentora da corrade aludita, e punia os que tinham acticas oisaus, religuass s ideias

Parín mo priédo medieral, as perssas ndo eram täs

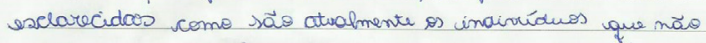
aceitam as religiös alkias, e inso foz que des sxiam mais ignorantes que is homens medierciso.

Segundo o ponal Defobro, as fius da religiäo wham dista a ao condomerei foram vrítimas de 22 das 53 dexiñ sias de intolurância religiosa. Mas ai the pergunto: Cossod pessoas the figerom algum mal, para que row desterpeite as? Talem do maios, w que the do soviecs de ridicularizar es demais?

Somos todos diferentes, e é isso que nos tarna únicos. iessas diferenças pedem e devom sor respeutacass no quesito religiäo equalquer sutro - Além do mais, essa deciná é assegurada a todo cidadäo brasiliiro, conforme consta na constituieăo. tmăa, mesmo sendo contra na oprião, temos o dever de respeitd-la

Figura 1
A avaliação/feedback foi registrada nos termos da avaliação textual, pois prevê o trabalho de reescrita pelo estudante, qualificando de modo positivo a retomada do texto e abrange comentários mais longos do que os que se efetuam na margem, motivo pelo qual são registrados em sequência ao texto do estudante. Tais comentários realizam-se na forma de "bilhetes". A primeira avaliação, ou seja, antes da reescrita, abrangeu questões de conteúdo e de atendimento ao gênero solicitado.

Após a entrega do feedback da primeira escrita, a professora solicitava aos estudantes que realizassem a reescrita de seus textos, isto é, que produzissem a segunda versão dos textos, considerando as avaliações que haviam sido apontadas. No que diz respeito ao feedback após a reescrita, nossa avaliação pontuou aspectos de conteúdo/gênero (quando necessário) e de intertextualidade em reflexões argumentativas.

Para a escrita final, a professora convidou os estudantes, após a entrega do feedback da reescrita, a produzirem uma última escrita de seus textos, ou seja, que registrassem a versão final de seus textos, considerando as avaliações pontuadas.

Escrita Final - Artigo de Opinião (Intolerância Religiosa) "Estudante Z"

$17 / 09 / 1$

Sousie

$$
\text { Plontar o respeito }
$$

A untrocouncia religiosa măs í um problema recente. Tala sompre ustere presente rra sociedade, um dos maicies exemplos disso foi a Reforma. Pro. testante, que scocreu mo século xiv caractoriza do por um merimento contra a

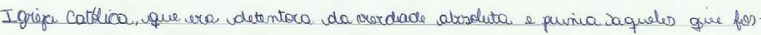

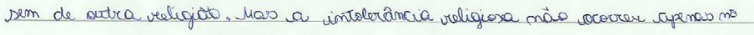

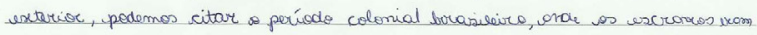

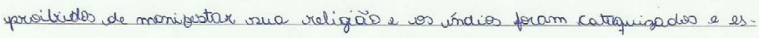
sa catequigacá poi uma verposta da ingreja cutólica a Reforma Protesta nte.

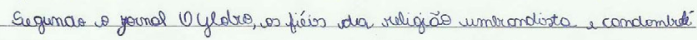
fecarm rutemas de 22 das 53 denuíncios de intedercincia veligiesa, denséncios que ners.

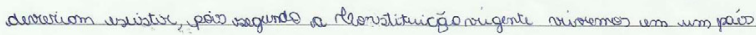
daico, vende caca um dere ou derrovia respeitar todas as a eliojiörs e as partocas que mä́ pasuem unma

$$
\text { boncordo com o que ding Drauzio varellea "Ourantas tragédias fo- }
$$

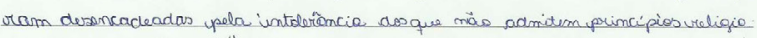

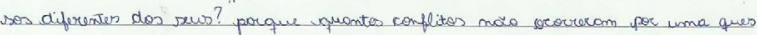
täs religiona, como os do Quiente Mídio que deinom muitos mortes, frides e refugiades. Além do inciso que justifica alguém achat sua religiño sapporior a de auta ser bumano? Isso mermo, nada!

Intäe, creio que deromes respeitor a reliquas do outbe, para que a morsa seja respeitida, que a aceitacedo das diforemcoss seja estimulada, tonto mas casas, escdas e que esse seja mair wum assunto a user debrabidoma midia. Io, deroremos plantar o respeds, para uque ele seefa cultinradomar sociedade, módo somente ma questäo raligiosa, moro ma de gémero, politica, etc 
Destacamos que nosso feedback após a escrita final dos textos concentrou-se em ratificar a intertextualidade para textos de cunho argumentativo, em alguns casos, e de sinalizar questões gramaticais como ortografia, pontuação e acentuação, basicamente.

Diante do exposto, apresentamos, a seguir, as considerações finais de nossas reflexões sobre o processo de ensino e aprendizagem de textos na Educação Básica, com base no referencial teórico-metodológico explorado.

\section{Conclusão}

No intuito de corroborar o que foi apresentado neste estudo, nos apoiamos na perspectiva da Linguística do Texto, que "é a perspectiva que vem fornecendo a base teórica mais usada no estudo da língua em sala de aula" (p.74)². Uma vez que o texto ativa estratégias, conhecimentos linguísticos e não linguísticos, a Linguística do Texto evidencia relevante abordagem no ensino e aprendizagem de língua ${ }^{2}$.

Destacamos, nesse sentido, que a Linguística do Texto é um aporte teórico que permite um trabalho teórico-prático, em sala de aula. Posto que a teoria concebe os sujeitos (professor e estudantes) como ativos na linguagem, e que preocupa-se com o texto enquanto processo de ensino e aprendizagem, permite, assim, o trabalho com produção textual, avaliação/feedback e reescrita de modo mais interativo e reflexivo.

A pesquisa-ação, é uma metodologia de pesquisa qualitativa, de âmbito social e educacional, que preconiza ação e participação em seu processo. A ação refere-se ao modo de realização do estudo, apresenta-se como uma intervenção diante de possível lacuna/fragilidade diagnosticada. Já a participação é uma atividade que reporta-se tanto aos pesquisadores como aos participantes da pesquisa, sujeitos igualmente ativos e corresponsáveis pelos resultados da(s) ação(ões) empreendida(s) ${ }^{16}$.

A pesquisa-ação, nos últimos anos, destacou-se como uma relevante metodologia de pesquisa no cenário educacional. Com a orientação da pesquisa-ação, estudiosos em educação conseguiriam produzir informações e conhecimentos de cunho mais pragmático, relacionados aos seus contextos de uso, principalmente no âmbito pedagógico, pois essa metodologia de pesquisa oportuniza a participação dos sujeitos envolvidos num mesmo processo, na busca de soluções às suas fragilidades/ problemas $^{16}$.

Nesse viés, corrobora-se quando sugere "que a aprendizagem de uma língua e a ação social que constrói e transforma o homem e o mundo são inseparáveis" (p. 83) ${ }^{18}$, pois a ação social solicita uma nova visão do que é educar: emancipar, auxiliar o estudante à autonomia cooperativa de seu processo de aprendizado. Esse meio de educar/agir é possibilitado na medida em que tanto professor quanto estudante se tornam investigadores de seu próprio processo de conhecimento.

Desse modo, pensamos ser importante sinalizar, aqui, que as definições e os conceitos de texto, sujeito e contexto, segundo a teoria de base de nossa pesquisa, evidenciam nossas concepções sobre relevantes questões que envolvem a sala de aula: o texto, o estudante e seu contexto de produção e recepção de textos. Além disso, nossas concepções acerca da avaliação/ feedback e da reescrita também revelam, de nossa parte, que acreditamos que a avaliação de textos pode e merece acontecer de modo participativo, em aula, e que a reescrita é um trabalho valioso de (re)pensar e avaliar nossas ideias.

Nesse sentido e, de acordo com nosso ponto de vista acerca do processo de ensino e aprendizagem de textos, na escola de Educação Básica, ressaltamos que tanto o arcabouço teórico da Linguística do Texto como o aporte metodológico da Pesquisaação favorecem o trabalho de produção textual, em sala de aula, especialmente com estudantes de Ensino Médio. O referencial teórico e metodológico aqui apresentado contribui para que o trabalho em sala de aula seja interativo, reflexivo e corresponsável, pois concebe os sujeitos como ativos nesse processo de ensino e aprendizagem e oportuniza a participação de todos os envolvidos na ação pedagógica.

\section{Referências}

1. Koch IV. Desvendando os segredos do texto. São Paulo: Cortez; 2002.

2. Marcuschi LA. Produção textual, análise de gêneros e compreensão. São Paulo: Parábola Editorial; 2008.

3. Koch IV, Elias VM. Ler e escrever: estratégias de produção textual. São Paulo: Contexto; 2012.

4. White R, ArndtV.Process Writing. London:Longman; 1991.

5. Motta VRA. Noticing e consciousness-raising na aquisição da escrita em língua materna. 2009. 204 p. Tese (Doutorado em Estudos Linguísticos) - Universidade Federal de Santa Maria, Santa Maria, RS.

6. Fávero LL, Koch IV. Linguística textual: introdução. São Paulo: Cortez; 2012.

7. Marcuschi LA. Linguística de texto - o que é e como se faz. São Paulo: Parábola Editorial; 2012.

8. Gomes-Santos SN, Santos LW, Santos MFO, Taffarello MCM, Travaglia LC. A contribuição da(s) teoria(s) do texto para o ensino. In: Bentes AC, Leite MQ. Linguística de texto e análise da conversação: panorama das pesquisas no Brasil. São Paulo: Cortez; 2010.

9. Bentes AC. Linguística textual. In: Mussalim F, Bentes AC. Introdução à linguística: domínios e fronteiras. São Paulo: Cortez; 2006. 
10. Marcuschi LA. Aspectos linguísticos, sociais e cognitivos da produção de sentido. Texto apresentado por ocasião do GELNE, 2-4 de setembro de 1998.

11. Koch IV. Introdução à linguística textual: trajetória e grandes temas. São Paulo: Contexto; 2015.

12. Beaugrande R, Dressler W. Introduction to text linguistics. New York: Longman; 1981.

13. Marcuschi LA. Linguística de texto - o que é e como se faz. Recife: UFPE; 1983.

14. Koch IV. Linguística textual: uma entrevista com Ingedore Villaça Koch. Revista Virtual de Estudos da Linguagem. 2003;1(1).

15. Burns AC. Collaborative action research for english language teachers. Cambridge: Cambridge University; 1999.

16. Thiollent M. Metodologia da pesquisa-ação. São Paulo: Cortez; 2011.

17. Dolz J, Schneuwly B. Gêneros orais e escritos na escola. Campinas: Mercado das Letras; 2004.

18. Richter M. Ensino do português e interatividade. Santa Maria: UFSM; 2000. 